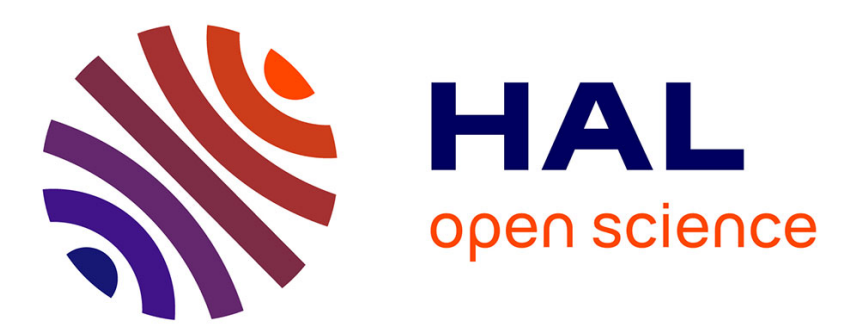

\title{
Financial Measures and Their Relations to Decoupling Points and Decoupling Zones
}

\author{
Joakim Wikner
}

\section{To cite this version:}

Joakim Wikner. Financial Measures and Their Relations to Decoupling Points and Decoupling Zones. IFIP International Conference on Advances in Production Management Systems (APMS), Sep 2015, Tokyo, Japan. pp.186-193, 10.1007/978-3-319-22756-6_23 . hal-01417462

\section{HAL Id: hal-01417462 \\ https://hal.science/hal-01417462}

Submitted on 15 Dec 2016

HAL is a multi-disciplinary open access archive for the deposit and dissemination of scientific research documents, whether they are published or not. The documents may come from teaching and research institutions in France or abroad, or from public or private research centers.
L'archive ouverte pluridisciplinaire HAL, est destinée au dépôt et à la diffusion de documents scientifiques de niveau recherche, publiés ou non, émanant des établissements d'enseignement et de recherche français ou étrangers, des laboratoires publics ou privés. 


\title{
Financial measures and their relations to decoupling points and decoupling zones
}

\author{
Joakim Wikner \\ Jönköping University, Jönköping, Sweden \\ joakim.wikner@decouplingpoints.org
}

\begin{abstract}
Financial management is concerned with the financial evaluation of activities performed in the supply chain. Each activity has implications on the financial situation but the actual cause-effect relation involved in this context is not always obvious. From a return on investment (ROI) perspective the financial measures revenue, cost, and assets, i.e. investment, are identified. Strategic leadtimes have been highlighted in the literature as key components for flow design. Strategic lead-times are thereafter further analyzed and the relations between financial measures and strategic lead-times are outlined. Based on these relations, it is possible to establish a relation between financial measures, and decoupling points and decoupling zones. Subsequently this is shown to also provide a reference to supply chain management strategies as they are defined in the literature.
\end{abstract}

Keywords: Decoupling points, strategic lead-times, financial measures

\section{Introduction}

Financial measures play a significant role in much decision making at a company level. Money in the bank has for long been a guiding star but as highlighted by e.g. Pierre S. du Pont the actual return obtained on the investment is the key measure. This return on investment (ROI) has since played an important role in the allocation of funds. Money is travelling from activities providing insufficient ROI to relatively more profitable investments and by using the so called DuPont scheme the ROI can be disintegrated into its constituent parts related to the balance sheet and the profit and loss statement respectively. In summary, the balance sheet provides the "investment" of ROI and the profit and loss statement provides the revenues and costs during a period. In short the ROI can be defined as the profit (revenues minus costs) divided by the assets in the balance sheet, which in some cases can be seen as the investment.

Even if Henry Ford once stated that "My idea was then and still is that if a man did his work well, the price he could get for that work, the profits, and all financial matters would care for themselves." [1, p. 44] the relation between "work well" and "profits" is, however, not always that obvious. Henry Ford, as the main owner of Ford, could trust his intuition on this but in most cases this is not possible. Frequently, the owners are not present in the operations, and are many times also not that interested in the operational details. Instead, the owners focus on the ROI of each period. In a stable

adfa, p. 1, 2011.

(C) Springer-Verlag Berlin Heidelberg 2011 
environment of mass production this approach works well as the system may be finetuned and compete based on economies of scale. Many companies are however facing a much more dynamic environment where in particular the demand changes rapidly due to for example short product life cycles. But, also supply can be dynamic in the sense that the dynamic demand puts pressure on the supply network to be able to respond to the demand changes. At an operational level these dynamics are much more perspicuous in the sense that the dynamics of demand and supply directly influence the capability of the system. These dynamics are known as the Forrester effect [2] or later the Bullwhip effect [3] and may be mitigated in several ways of which changes to the structure of the supply chain, the reduction of lead-times and simplification of information flows are important. One common theme here is the lead-times of the supply chain. Lead-time management has developed in many directions over the years and is a corner stone of e.g. time-based management [4], lean thinking [5], and decoupling thinking, see e.g. [6,7]. All these approaches focus on lead-time and efficient use of resources but still the connection between different lead-times and ROI is not that well investigated in the literature. The purpose here is therefore to outline relations between the financial measure of ROI and the key lead-times, i.e. the strategic lead-times.

Next, decoupling layers are outlined and then financial measures are further analyzed followed by an overview of strategic lead-times in the context of decoupling thinking. Finally, the two areas of financial measures and decoupling based on strategic lead-times are combined and some conceptual relations between ROI and strategic lead-times are identified and illustrated in a decoupling framework.

\section{The decoupling layers}

Management in general is a challenging subject and Wikner [7] suggests that three distinct system perspectives can be used to focus on different aspects. At a fundamental level there is a logical perspective where the transformation is in focus (see Fig. 1). This layer is associated with process management which can be divided into a meta level of flow constructs and a higher level of constructs focusing on specific decision categories. The details of the logical perspective are further described in [7]. The physical perspective is based on the fundamental flow logic but employs these constructs in terms of supply chain management strategies where the type of transformation is important and this is further outlined in [8]. Finally, all these transformations must be interpreted in terms of economic consequences where the actual sponsor of the transformation is identified and this is the subject of this paper.

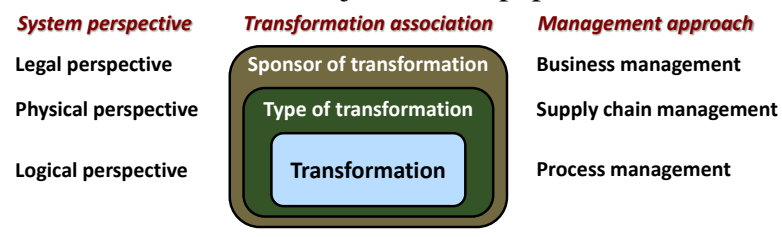

Fig. 1. The three perspectives legal, physical, and logical [7]. 


\section{$3 \quad$ Financial measures}

As pointed out initially the key fundamental financial measure is return on investment (ROI). ROI can be defined in different ways, depending on what the "investment" represents, but the key point is that the result obtained should be put in relation to the size of the investment. The result is the Profit obtained, from the profit and loss statement, and expressed per time period and referred to as Revenue minus Cost, i.e. Profit $=$ Revenue-Cost. In throughput accounting [9] the ROI is based on the throughput, operating expenses and inventory but the result is the same except for some effects due to allocation to different periods. In addition, the size of the investment is here represented by the Assets in the balance sheet. As a consequence, the ROI can be calculated as: ROI $=($ Revenue - Cost $) /$ Assets and each of these three components are further elaborated on below. Note that this particular definition of ROI corresponds to return on assets (ROA). But, since the key message here is the significance of the relative property of the measure the more general name ROI is used below.

Revenue is based on income and is defined as the income allocated to different periods. The revenue generating capability of an offering is correlated to the competitiveness of the offering. The competitiveness of the business is thus an important factor for the revenue generating capability. For example, if the market requests customization it usually indicates that the customer can accept some delivery lead-time but also that the business must have flexibility for customization to generate the revenue. Correspondingly, a focus on low price usually indicates that the market can accept a more standardized offering, i.e. a commodity, but then available within a short lead-time. As a consequence, the revenue is dependent on the lead-time facing the customer and the capability of the company to use this lead-time to provide a competitive offering.

Costs are related to expenses and can be categorized in different ways. A frequently used approach is to divide costs into direct and indirect costs. The two key components in direct costs are directly attributed to the cost object and are direct material (DM) and direct labor (DL). Indirect costs are then allocated to the cost objects on some basis that is usually related to direct costs such as resources used during a lead-time.

Assets, as used here, concern both materials and capacity. Materials are related to the expected scenarios such as the expected lead-time for a flow section which will contain a certain amount of material in relation to the lead-time. The other aspect refers to unexpected events and buffers that are introduced to protect against these unexpected events. Capacity is less directly related to lead-times but obviously outsourcing reduces the level of own capacity at the expense of higher costs for direct materials.

\section{$4 \quad$ Financial measures and strategic lead-times}

There are six types of strategic lead-times that are of particular interest here and can be seen as aggregate reflection of certain perspectives of performed activities, see e.g. [7]. On the supply side, the cumulative lead-time (S) is fundamental but also the division of the lead-times into internal (I) and external (E) is important as it refers to the controlla- 
bility of the activities. In addition, the capability to create customized solutions is related to the customization that could be created based on the properties of the product. These properties can be created certain lead-time before delivery and this is referred to as the supply based adapt lead-time $\left(\mathrm{A}_{\mathrm{S}}\right)$. The $\mathrm{A}_{\mathrm{S}}$ hence represents the capability of the business to provide a customized solution (in the figure it is $A_{S}$ for item $U$, hence the notation $\mathrm{A}_{\mathrm{S}, \mathrm{U}}$ ). On the demand side the requested delivery lead-time (D) is key. However, it is important to note that $\mathrm{D}$ is not related to level of customization, but only to how long time before delivery that the customer order is obtained. The distinction between requested customization and standardization is instead covered by the demand based adapt lead-time $\left(A_{D}\right)$. These strategic lead-times $\left(S, I, E, A_{S}, D\right.$, and $\left.A_{D}\right)$ are illustrated in the example of Fig. 2 Note that the strategic lead-times, E and I, are unique for each branch of the bill-of-material and that there can be several $\mathrm{A}_{\mathrm{S}}$ depending on the properties of the bill-of-material. Next, these strategic lead-times are investigated based on their impact on some financial measures.
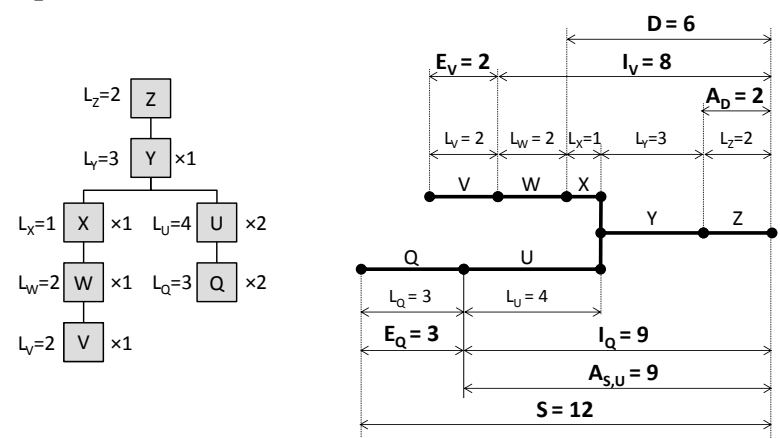

Fig. 2. Example of material-based and lead-time-based bill-of-materials [7].

\subsection{External lead-time (E) and Internal lead-time (I)}

External lead-time (E) is defined for each branch of the time phased bill-of-material. E is based on the lead-time that is external to the logical entity and is usually related to purchased material that is considered as direct material cost (DM). Correspondingly, the internal lead-time (I) is based on transformation that is performed on the direct material and is hence related to the direct labor cost (DL).

In addition, I represents the time the item spends in the system, and thus also the value of the item. Consequently, it is related to the amount of material in the system, also referred to as work in process (WIP) inventory. A measure of the extent is provided by Little's formula that tells us that the amount of material in the system is related to the flow rate multiplied by the lead-time, which in this case is I for that item. In a similar manner, $\mathrm{E}$ is related to the replenishment lead-time from suppliers and due to both the lead-time and the potential uncertainty in the external lead-time the magnitude of $\mathrm{E}$ may impact assets in terms of raw material inventory, c.f. safety lead-times.

Note that this discussion refers to the main impact. From a more general perspective it could be argued that the ratio of $\mathrm{E}$ and I indicates the use of external capabilities that 
may also contribute to impact revenues. This ratio could be altered by e.g. outsourcing parts of the activities. However, these "side effects" are not emphasized here.

In summary, I and E are both important from a cost perspective as well as from an asset perspective. E is related to DM and raw materials inventory, and I impacts the assets in terms of capital tied up in the flow, also known as WIP inventory.

\subsection{Supply lead-time (S) and Delivery lead-time (D)}

Both the supply lead-time (S) and the delivery lead-time (D) are important from a risk perspective where $S$ indicates where the provider must start taking a material based supply risk and D is where the supply risk is neutralized in the sense that the provider does not need to speculate any more due to that the customer has made a decision, i.e. released a customer order. $\mathrm{S}$ can be defined from a product perspective and from an item perspective. The product perspective refers to the longest cumulative lead-time of the complete product structure. This lead-time was originally referred to as the product lead-time (P) [10]. The item perspective is not as frequently used and represents the cumulative lead-time for each individual item considering the items above the item in the product structure [11]. Here, the focus is on the product based S. D represents the delivery lead-time requested by the market and corresponds to how long before the actual delivery that the supplier does not have to take the supply risk. At this time the customer has decided about the customer order and hence the supplier can perform the transformation to customer order, i.e. under certainty about demand.

$\mathrm{S}$ and $\mathrm{D}$ are also significant in how they interact. $\mathrm{S}$ is on the supply side and represents characteristics of the supply capability. D is on the demand side and represents the point in time in the planning horizon where the properties of demand changes from forecast-driven to customer-order-driven. $\mathrm{S}$ indicates the part of the planning horizon with released or firm planned orders in line with the planning time fence (PTF). It represents the time span within which the materials available are constrained. D represents the positioning of the customer order decoupling point (CODP) [12] and also the demand time fence (DTF) and this is where the uncertainty for planning is further reduced. The relation between time fences and S and D is further outlined in [7]. Since S, and in particular S-D, is based on speculation it is also where WIP is most likely to accumulate and impact assets in an additional way.

In summary, D affects the positioning of a key buffer point, the CODP, and as a consequence also capital tied up, i.e. assets. In addition, it is a key lead-time for creating a competitive advantage and thus represents an opportunity for increasing revenues. S is mainly a measure of where material-based speculation needs to be initiated and hence where the preconditions for buffers are initiated at the latest.

\subsection{Adapt lead-time based on demand ( $\left.A_{D}\right)$ and supply ( $\left.A_{S}\right)$}

The adapt lead-time is related to the customization of the product. Basically there are two possible perspectives on customization [13]. The market oriented is the demand based adapt lead-time $\left(A_{D}\right)$ based on the customers' requirements on customization. 
The second perspective is related to supply and if the product has untapped possibilities for creating customization. This is basically unused potential in the product and is usually related to particular items that provide this opportunity and this adapt lead-time is called supply based adapt lead-time ( $\left.\mathrm{A}_{\mathrm{S}}\right)$. The market based customization has obvious potential for increased revenue. For the supply based customization this relation is not as obvious, since it has not been requested by the market, and the potential cost impact is more significant since it e.g. would result in more variants.

In summary, the two types of adapt lead-time both impact revenue but as noted there is also a direct relation to costs for As.

\subsection{Summary of financial measures and strategic lead-times}

Three financial measures have been identified based the fundamental definition of return on investment, ROI. As indicated in Fig. 3, the demand based lead-times mainly impact revenues and the supply based mainly impact cost and assets. Revenue is created by the customers and hence the demand based strategic lead-times represent revenue opportunities. The delivery lead-time $\mathrm{D}$ is the time the customer waits for delivery and the adapt lead-times are related to customization. The adapt lead-time requested by the market $\left(A_{D}\right)$ also represents the shortest possible delivery lead-time but, if still competitive, a $\mathrm{D}$ that extends even further upstream reduces the risk of the supplier and the need for buffers which is a consequence on the asset side.

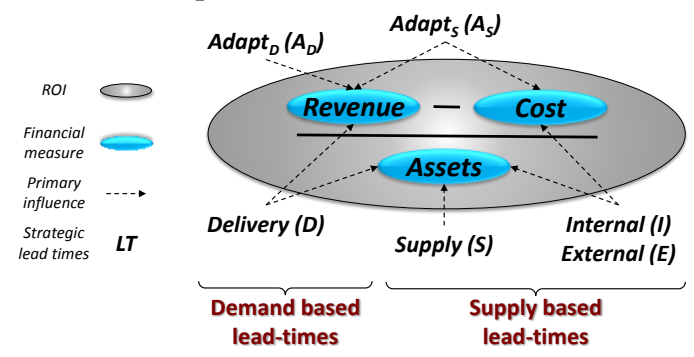

Fig. 3. ROI, financial measures and the strategic lead-times.

The supply-side affects assets most obviously in terms of E (raw-materials inventory) and I (work-in-process inventory). Note that I is related to a logical entity [7] which could involve for example a single site or a network of sites. The key message here is that everything upstream from I would be considered as DM. In addition, there is some impact on assets from $\mathrm{D}$, on the demand side, since the positioning and dimensioning of the CODP buffer is based on properties of D. From an inventory perspective this means that the three strategic lead-times E, I, and D correspond to the three categories of inventory from an accounting perspective, i.e. raw materials inventory, work-in-process inventory and finished goods inventory (which is a special case of CODP inventory). S, finally, also impacts assets from the supply side but it is a separate case as it is not related to one particular class of inventory but it is rather the baseline for when plans must be firmed (c.f. PTF) and hence this indicates a shift to less flexibility to 
changes in the planning horizon. The strategic lead-times I and E have obvious relation to cost as they are related to the two main categories of direct costs, i.e. DM and DL, and in addition also the allocation of indirect costs since DM and DL are often used as a basis for allocation. E and I also provide some insights on the ratio between DM and DL. The types of activities involved are however not known from a general perspective and the actual magnitude of the costs cannot be observed. Finally, As indicates potential future customization offerings and as such it is not only a revenue opportunity but also a source of additional cost if the opportunity is exploited.

\section{$5 \quad$ Financial measures and the decoupling framework}

The strategic lead-times can be used in positioning of strategic decoupling points where $A_{D}$ (A in Fig. 4), D, and I are of particular interest. These three lead-times indicate the position of three strategic decoupling points: Customer order decoupling point (CODP), Customer adaptation decoupling point (CADP), and Purchasing order decoupling point (PODP). These three types of decoupling points are illustrated in Fig. 4 and the corresponding buffer points are illustrated with black triangles. The three financial measures used in ROI are also included in the figure and positioned based on their respective relation to the strategic lead-times, as outlined above and illustrated in Fig. 3.

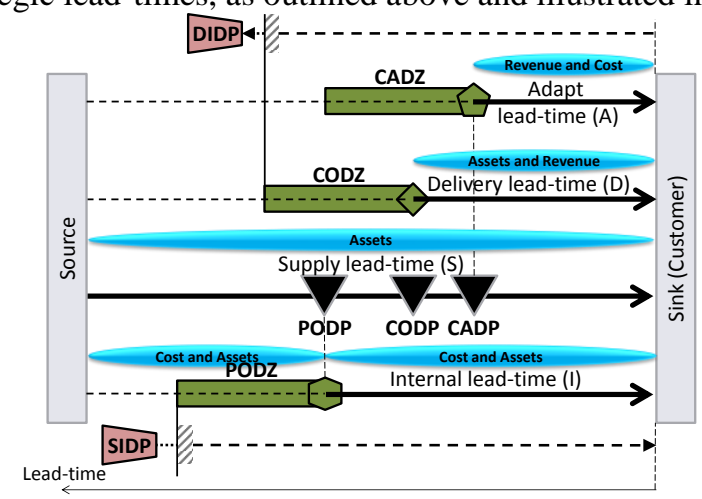

Fig. 4. Financial measures and the decoupling framework.

The three decoupling zones CODZ, CADZ, and PODZ represent a mix of conditions before and after each zone (the $\mathrm{Z}$ in the zone acronyms represents Zone) (see e.g. [7]). For example, CODZ is the customer order decoupling zone and is related to a compromise between forecast and customer orders. Two of these zones also represent the condition for positioning of the demand information decoupling point (DIDP) and the supply information decoupling point (SIDP), both related to information transparency. The fundamental framework in Fig. 4 is thoroughly discussed and defined in [7]. In [8] it is shown how eight different supply chain management strategies can be interpreted in terms of a decoupling framework. This is here extended to also involve financial measures. Further research will involve empirical investigation of the relationships between financial measures and strategic lead-times. In particular the companies involved 
in this research has expressed interest in the measure "cost of lead-time" but as shown here also revenue and assets may play a significant role.

\section{Acknowledgement}

This research has been performed in collaboration with five companies in the project KOPtimera. The project is funded by the Swedish Knowledge foundation (KKS), Jönköping University and the participating companies.

\section{References}

[1] H. Ford and S. Crowther, My Life and Work: Doubleday, Page, 1922.

[2] J. W. Forrester, "Industrial dynamics: a major breakthrough for decision makers," Harvard business review, vol. 36, pp. 37-66, 1958.

[3] H. L. Lee, V. Padmanabhan, and S. Whang, "Information distortion in a supply chain: the bullwhip effect," Management science, vol. 50, pp. 1875-1886, 2004.

[4] G. Stalk and T. M. Hout, Competing against time : how time-based competition is reshaping global markets. New York: Free Press, 1990.

[5] J. P. Womack and D. T. Jones, Lean thinking : banish waste and create wealth in your corporation, 1st Free Press ed. New York: Free Press, 2003.

[6] S. Hoekstra and J. Romme, Eds., Integral logistic structures: developing customer-oriented goods flow. New York: Industrial Press, 1992.

[7] J. Wikner, "On decoupling points and decoupling zones," Production \& Manufacturing Research, vol. 2, pp. 167-215, 2014.

[8] J. Wikner, "Supply Chain Management Strategies in Terms of Decoupling Points and Decoupling Zones," in Advances in Production Management Systems. Innovative and Knowledge-Based Production Management in a Global-Local World. vol. 438, B. Grabot, B. Vallespir, S. Gomes, A. Bouras, and D. Kiritsis, Eds., ed: Springer Berlin Heidelberg, 2014, pp. 371-378.

[9] E. M. Goldratt and J. Cox, The goal : a process of ongoing improvement, Rev. ed. New York: North River Press, 1986.

[10] S. Shingō, A study of the Toyota production system from an industrial engineering viewpoint, Rev. ed. Cambridge, Mass.: Productivity Press, 1989.

[11] J. Bäckstrand, "A Method for Customer-driven Purchasing : Aligning Supplier interaction and Customer-driven manufacturing," School of Engineering, Jönköping University, Jönköping, 2012.

[12] H. Mather, Competitive manufacturing: CRC Pr I Llc, 1999.

[13] J. Bäckstrand and J. Wikner, "Time-phasing and decoupling points as analytical tools for purchasing," in proceedings from the IEEE International Conference on Industrial Engineering and Engineering Management Bangkok, Thailand, 2013. 